\title{
The Impact of Changes in the FTSE 100 Index
}

\author{
Bryan Mase $^{\text {: }}$
}

\begin{abstract}
This paper examines both the long-term and short-term impact associated with changes in the constituents of the FTSE 100 Index. We find that stocks exhibit positive (negative) abnormal long-run performance following their inclusion in (deletion from) the index. There is also evidence of significant short-term cumulative abnormal returns around the event. The reversal of these price effects suggests that short-term buying (selling) pressure (possibly from index trackers) moves prices temporarily away from equilibrium. An analysis of stock liquidity implies speculators may trade in advance of the announcement, while index trackers trade between the announcement and event dates. Finally, the organisation of the FTSE 100 Index enables us to conduct an analysis of stocks that just avoid being relegated from (fail to be promoted to) the FTSE 100.
\end{abstract}

JEL classification: G14

Keywords: Index trackers; Liquidity; Listing; Long-run performance.

\footnotetext{
* Dr. Bryan Mase, Dept. of Economics and Finance, Brunel University, Uxbridge, Middlesex, UB8 3PH.

Tel: (44) 1895 - 203166;

Fax: (44) 1895 - 203384;

e-mail: bryan.mase@brunel.ac.uk
} 


\section{Introduction}

The analysis of the impact of a stock's inclusion in (or deletion from) a stock index is of interest because it is an event that should be dependent on information that is public at that time. In contrast to the S\&P 500 Index, changes in the composition of the FTSE 100 Index are based purely on the relative market capitalisation of the respective firms. If its inclusion in the index has a value to a particular firm, then this can only be by way of a change in the demand for its stock. In particular, if index inclusion (deletion) leads to an increase (decrease) in demand, then the nature of the price effects observed around index changes can shed light on the specific determinants of the price effects. If the demand curve for stocks is downward sloping, an increase (decrease) in demand will lead to a permanent increase (decrease) in price, consistent with the absence of perfect substitutes. Alternatively, a temporary price effect is consistent with temporary price pressure, as increased demand pushes the price up and compensates traders for providing liquidity. Finally, a permanent price and liquidity effect is consistent with index membership increasing stock liquidity. Thus not only can we investigate how changes in demand that are unrelated to information events influence prices, we can also distinguish between the competing explanations for the observed price effects.

An investigation into the effect of changes in the composition of the FTSE 100 Index extends the current research in this area in a number of ways. First, we examine the long-term performance of firms added to, or deleted from, the FTSE 100. This will enable us to quantify the implicit value to a firm of being included in the FTSE 100 Index. Previous research has focused only on the short-term patterns in returns and volume around the announcement and effective dates of index changes. A possible driving force behind abnormal long-term performance is the demand for stock by index trackers (an index fund makes purchases or sales in order to ensure that the fund mimics the composition, and therefore the performance, of the index). Indeed there is some 
evidence to suggest that this may be the case. It has been found that institutional ownership increases after a stock is listed in an index (Pruitt and Wei 1989).

Alternatively, demand could be influenced by stock liquidity, a liquid stock being one with relatively low transaction costs and a high degree of publicly available information. This research therefore allows consideration both of the impact of index funds and the apparent relation between the value of a stock and its liquidity.

Second, as noted below, research to date has focused on changes in the composition of US indices, where changes are driven by the need to remove stocks (normally as a result of a merger). It can be argued that index inclusion in, for example, the S\&P 500 does have information content because the decision to include a stock is based on factors other than just the size of the firm. In particular, an attempt is made to avoid repeated changes in index composition - Standard and Poor's states that every effort is made to avoid excessive turnover. Thus index inclusion may be informative about a stock's expected future performance. As Kaul, Mehrotra and Morck (2000) argue, a stock's inclusion in the S\&P 500 is likely to be a favourable signal about that stock's financial health, particularly since the decision emanates from a credit rating agency. This study instead focuses on changes in index composition that are induced by a series of regular quarterly rankings. As a result, these changes should have absolutely no information content.

Finally, because the inclusion/deletion decision is based solely on relative market capitalisations, we are able to extend our analysis to consider those firms that just avoid being relegated from, just fail to be promoted to, the FTSE 100. This unique analysis of what might be termed 'nearly' firms will help to shed light on the extent to which trading

\footnotetext{
${ }^{1}$ Amihud and Mendelson (1986) identify a negative relation between the bid-ask spread (a measure of liquidity) and the expected return on a stock, while Amihud, Mendelson and Lauterbach (1997) find that a liquidity enhancing change in market microstructure had a positive impact on returns.
} 
occurs in anticipation of the quarterly ranking. The 'nearly' firms are of interest because they should not be influenced by funds that attempt to track the index. Contrasting their results with those associated with the included/deleted firms should give a clearer picture of the trading patterns induced by index trackers.

\section{Literature}

While there is no published research on the long-term impact of changes in index composition, there is consistent evidence of short-term price effects associated with index changes, particularly index inclusion. The precise implications of these short-term price effects are disputed. On the one hand, if there is information content in the decision to include a stock in an index, an associated price effect is simply a response to new information. On the other hand, if changes in index composition are information neutral, then the permanence of the observed price and liquidity effects associated with membership may enable us to distinguish between three competing hypotheses. A downward-sloping demand curve requires the price effects to be permanent, while the reversal of the price effects after the event is consistent with temporary price pressure. Finally, a permanent price effect together with an associated increase in liquidity after the event implies that current prices reflect a reduction in expected transaction costs.

Shleifer (1986) hypothesises that a firm's inclusion in an index might induce significant buying by institutions attempting to track that index. He finds a significant abnormal post-announcement return of just under 3\% for firms added to the S\&P 500 Index after 1976. ${ }^{2}$ There is also a positive relation between abnormal returns and abnormal volume at the time of announcement. A similar analysis by Harris and Gurel (1986) also finds evidence of a significant price effect following the announcement of a

\footnotetext{
${ }^{2}$ The year announcements of changes to the index were made more precise.
} 
stock's inclusion in the S\&P 500 Index over the latter half of the 1973-1983 period. While both studies reject an information-signalling hypothesis, there is disagreement about the precise implications of these findings. The absence of a return reversal enables Shleifer (1986) to argue that his results are consistent with downward sloping demand curves. Harris and Gurel (1986) find a full price reversal after approximately three weeks, and therefore support the temporary price pressure hypothesis. Dhillon and $_{\text {Dh }}$ Johnson (1991) find that the effect on prices is not reversed in the post-1983 sample, which they tentatively attribute to the advent of derivatives trading. They suggest that the positive price effect may be attributable to information, given the associated positive price effects on an included firm's bonds.

In 1989, S\&P introduced a new announcement policy to overcome the buying pressure observed in the above studies. Since then, changes to the S\&P 500 have been announced five days before the effective date. The impact of this change in policy is examined by Beneish and Whaley (1996). They show that stocks added to the S\&P 500 between 1989 and 1994 exhibit positive abnormal returns between the announcement and effective dates that are only partially reversed after the change is made. Further, they suggest that the abnormal return has increased over time, consistent with risk arbitrageurs trading in advance of the change date. Finally, Lynch and Mendenhall (1997) examine both additions and deletions made to the S\&P 500 between 1989 and 1995 . They find significant positive (negative) abnormal returns following the announcement of an addition (deletion). Using post effective date windows of 7 days for additions and 5 days for deletions, they find significant, but partial, return reversals. Further, trading volume is

\footnotetext{
${ }^{3}$ The price pressure hypothesis was first proposed by Scholes (1972). It suggests a temporary price effect as a result of high demand moving prices temporarily above their equilibrium values. This is in contrast to the imperfect substitutes hypothesis, which would produce a permanent price effect due to the nonavailability of equivalent stocks.
} 
significantly higher from the announcement date, and is particularly large on the day prior to the effective date. There is no evidence of abnormal volume prior to the announcement. They conclude that these findings are consistent with a combination of both temporary price pressure effects induced by index trackers, and downward sloping demand curves for stocks.

Beneish and Gardner (1995) examine changes in the composition of the Dow Jones Industrial Average (DJIA), noting that the DJIA is not tracked by index funds. They find little impact on the stock price or trading volume of added firms, although deleted firms experience significant negative excess returns at the time of the announcement, and their trading volume is subsequently reduced. These results are consistent with liquidity and information costs, rather than explanations based on price pressure or imperfect substitutes. Finally, Kaul, Mehrotra and Morck (2000) examine a change in rules relating to index weights in the TSE 300 Index that took place in 1996. This change had been pre-announced and had no information content. They find that 31 stocks undergoing an increase in index weight had significant excess returns in the effective week averaging $2.34 \%$. The absence of a subsequent price reversal enables them to conclude that these findings support downward sloping demand curves.

\section{Data}

The organisation of the FTSE 100 Index is undertaken by the FTSE Steering Committee, which conducts a quarterly review of FTSE 100 constituents. Until April 1992, this review was held during the penultimate weeks of March, June and September and the second week of December, with constituent changes being implemented on the first business day of the following month. Following a change in the expiration of futures and options contracts, since April 1992 the review has taken place in the second week of the month, changes then being implemented on the Monday after the third Friday of the 
contract month. As a result, there is now a consistent number of trading days between the announcement and event dates. At review, inclusion is automatic if a stock reaches the 90th position by capitalisation. Similarly, exclusion is automatic if a stock moves below the 110th position. In order to maintain stability, the Index will therefore not necessarily incorporate the 100 largest stocks at any particular time. After review, the FTSE 100 will include the 90 largest stocks, plus 10 of the next 20 largest, i.e. 10 stocks ranked between 91 and 110. Thus, for example, a stock ranked 95th would not be included automatically, but may be included if it is the largest capitalised stock outside the index and a current constituent falls below the 110 th position. The only certainty for stocks ranked in this 'grey area' between 91 and 110 is that a stock will not be added to the index if it ranks below 100, while a stock will not be relegated if it ranks 100 or higher. For stocks ranked $91-100$ there is a probability of inclusion, while for stocks ranked 101-110, there is a probability of exclusion.

This procedure means that there is no uncertainty regarding the changes made by the Steering Committee once the stocks are ranked. There will, in addition, be a certain degree of predictability prior to the announcement, this predictability increasing as the point at which the ranking is made approaches. This predictability will be blurred since a stock's inclusion or deletion is dependent not just on its own performance prior to review, but also on the performance of stocks that may themselves be deleted or included. As a result, a market participant interested in the outcome of the quarterly review should be able to make reasonably accurate predictions of the changes that are likely, but only shortly before the announcement date. It is this feature of the organisation of the FTSE 100 Index that contrasts strongly with the determination of the constituents of the S\&P 500. The latter has been likened to a 'game,

\footnotetext{
${ }^{4}$ See Beneish and Whaley (1996).
} 
the index when a stock has to be removed, e.g. due to merger or liquidation. The added stocks are selected on the basis of a number of criteria, including liquidity, size, industry and financial soundness. In addition, an attempt is made to avoid excessive turnover of stocks within the index. This means that there is likely to be a degree of subjectivity in the choice of newly added firms, to the extent that the decision may be regarded as being informative about a firm's prospects. Our analysis should capture more explicitly the impact of the trading behaviour of index trackers and others, given the absence of an associated information event.

Changes in composition are also made outside of the quarterly review, generally as a result of a new issue or merger. Additions to the index between reviews are made from a ranking of the six stocks that comprise a reserve list, while a new issue ejects the smallest capitalised constituent at the time. Such changes are relatively infrequent, occurring approximately 2 or 3 times a year. For these changes, the effective date is normally the day succeeding the announcement.

We examine the inclusions and deletions that take place between 1/4/92 and 1/4/99. This period coincides with an increase in the popularity of index tracking in the UK. For example, it is currently estimated that approximately $70 \%$ of UK pension funds are managed, either explicitly or implicitly, by index trackers. ${ }^{\text {B }}$ Our analysis is in two distinct parts. The first represents an investigation of the long-term performance of firms that are included in, or removed from, the index. The second examines the short-term price and volume effects around the announcement and event dates of additions and deletions, as well as those categorised as 'nearly' firms - those that just fail to be included or just avoid being deleted.

\footnotetext{
${ }^{5}$ The Financial Times, January (1999).
} 
4 Results

\subsection{Long Horizon Returns}

We first examine the long-term benefit to a stock of being included in the FTSE 100 Index. It is possible that increased investor interest, either as a result of index tracking or increased publicity, has a positive impact on the long-run stock returns of firms included in the index. Similarly, we might expect a negative impact on the returns of the deleted firms. Naturally, measuring the long-run performance of such stocks cannot include the pre-announcement return period, since it is return performance during this period that results in a stock either being included in, or deleted from, the index. Since index membership is determined by a stock's relative market capitalisation, it is likely that stocks added to the index exhibit relatively superior return performance prior to the announcement, and vice versa for deleted stocks.

It has recently been shown that the conventional approach used in the measurement of long-run abnormal returns may be inappropriate. In particular, Barber \& Lyon (1997) and Kothari and Warner (1997) identify a number of causes of misspecified test statistics, including new listing and rebalancing biases, resulting from the use of reference portfolios to calculate abnormal returns. Barber \& Lyon (1997) suggest that abnormal returns be measured by buy-and-hold returns of sample firms less buy-and-hold returns of matching control firms. They argue that 'the control firm approach yields test statistics that are well-specified in virtually all sampling situations that we consider.'

Following Barber \& Lyon (1997), we compute buy-and-hold returns for each sample and matched (or control) firm over the following one and three year period. The matching procedure we apply controls for both size and industry effects. In order to avoid the impact of the pre-announcement run-up, we compute these returns from the announcement date. In addition, we find below temporary price pressure associated with 
the event. We therefore also measure the three-year post-event returns, starting 21 days after the event date (by which time the market has fully absorbed the temporary buying and selling associated with the index changes). All the sample firms are matched with corresponding firms that have the same two-digit industry classification, and are closest to the sample firms in market capitalisation within that particular classification. If the sample firm subsequently delists during the estimation period, we assume that the proceeds are invested in the matched firm. If the matched firm delists, the next closest matched firm is substituted at that point. ${ }^{6}$ Abnormal buy-and-hold returns (BHAR) measured over some time period $\tau$ are calculated as

$$
\operatorname{BHAR}_{\mathrm{i} \tau}=\Pi_{\mathrm{t}=1}^{\tau}\left[1+\mathrm{R}_{\mathrm{it}}\right]-\Pi_{\mathrm{t}=1}^{\tau}\left[1+\mathrm{R}_{\mathrm{jt}}\right]
$$

where $R_{i t}$ is the sample firm return and $R_{j t}$ is the matched firm return. We use a skewness-adjusted t-statistic to determine the significance of the mean abnormal buyand-hold returns. ${ }^{\mathrm{B}}$ This skewness-adjusted test statistic is

$$
\mathrm{t}_{\mathrm{sa}}=\sqrt{\mathrm{n}}\left(\mathrm{S}+\frac{\hat{\gamma} \mathrm{S}^{2}}{3}+\frac{\hat{\gamma}}{6 \mathrm{n}}\right)
$$

where

$$
S=\frac{\overline{\mathrm{BHAR}}_{\tau}}{\sigma\left(\mathrm{BHAR}_{\tau}\right)}, \text { and } \hat{\gamma}=\frac{\sum_{\mathrm{i}=1}^{\mathrm{n}}\left(\mathrm{BHAR}_{\mathrm{i} \tau}-\overline{\mathrm{BHAR}}_{\tau}\right)^{3}}{\mathrm{n} \sigma\left(\mathrm{BHAR}_{\tau}\right)^{3}}
$$

Critical values for this transformed test statistic are obtained from the test statistic calculated from 1000 bootstrapped resamples from our sample of individual firm abnormal returns $\left(\mathrm{BHAR}_{\mathrm{i \tau}}\right)$. Each resample is of size n/3 (Lyon, Barber and Tsai (1999) suggest that resample sizes between $\mathrm{n} / 2$ and $\mathrm{n} / 4$ yield well-specified inferences).

\section{Insert Table I}

\footnotetext{
${ }^{6}$ See, for example, Vijh (1999) and Desai and Jain (1999).

${ }^{7}$ The use of this test statistic was proposed by Lyon, Barber and Tsai (1999).
} 
Table I reports the long-horizon return results for both the additions and deletions, measured over one and three-year intervals. There is evidence consistent with positive buy-and-hold abnormal returns over a one and three-year period following a stock's addition to the FTSE 100. For example, the mean abnormal returns over a threeyear holding period are $17.61 \%$ measured from the announcement day and $20.93 \%$ measured from 21 days after the effective date. Column 5 of Table I shows that the results for the deletions are less strong, but consistently negative. Stocks deleted from the index yield three-year abnormal buy-and-hold returns of $-16.41 \%$ from the announcement day and $-19.31 \%$ from 21 days after the effective date. As noted above, the basis for a stock's addition to, or deletion from, the FTSE 100 index must reflect its relative performance prior to the announcement. These results demonstrate that this relative performance continues for up to three years after the change in FTSE 100 constituents. It is unlikely that this can be explained by a momentum effect. Return continuation is generally observed over time periods of up to one year following portfolio formation, and is strongest over a six-month horizon. ${ }^{8}$ The alternative explanation is that these results reflect the long-term impact of increased (reduced) investor interest in additions (deletions), possibly as a result of index tracking.

\subsection{Short Horizon Returns}

The analysis below again focuses on the period between 1/4/92 and 1/4/99 because this coincides with the use of consistent six-day windows between announcement and effective dates at the quarterly review. This contrasts with Lynch and Mendenhall (1997), who analyse events for which there are a variable number of days

\footnotetext{
${ }^{8}$ See Jegadeesh \& Titman (1993) and Rouwenhorst (1998).
} 
between announcement and effective dates. ${ }^{0}$ We identify the announcement and event dates for all inclusions and deletions. We exclude any changes for which there is not the standard six trading days between the announcement date $(\mathrm{t}-7)$ and the event date $(\mathrm{t})$. Both the announcements and the changes in index composition occur after close of business, so we take the following day as the announcement and event dates respectively. The six-day window requirement confines the sample to the quarterly reviews, a total of 66 additions and 66 deletions. The ability to identify the announcement and event dates is important because it enables us to distinguish between trading that might anticipate the announcement, and trading that takes place between the announcement and event dates (when the actual change in constituents takes place). It also enables us to examine the actual pattern in trading between the two dates.

We use an event study methodology to examine the impact of both the announcement and the event itself on the returns of the firms. Abnormal returns are calculated using the market model

$$
\mathrm{R}_{\mathrm{it}}=\alpha_{\mathrm{i}}+\beta_{\mathrm{i}} \mathrm{R}_{\mathrm{mt}}+\varepsilon_{\mathrm{it}}
$$

where $\mathrm{R}_{\mathrm{it}}$ and $\mathrm{R}_{\mathrm{mt}}$ are the returns to security $\mathrm{i}$ and the market on day $\mathrm{t}$. The abnormal returns relating to the event are $\varepsilon_{\mathrm{it}}$, the model parameters normally being estimated over some period prior to the event. ${ }^{10}$ The difficulty with an analysis of index inclusions and deletions is that the market model requires the event to be exogenous to the performance of the firm. This is clearly not the case given that the event is determined by the relative

\footnotetext{
${ }^{9}$ The benefit of a consistent number of days between announcement and change dates is that the precise pattern of returns or volume can be obtained. Lynch and Mendenhall (1997) are unable to examine the movement in returns or volume in such detail, displaying the daily abnormal returns or volume between the two dates as the mean divided by the average number of days over the interval.

${ }^{10}$ A simpler version of the market model, the market adjusted return, constrains $\alpha_{i}=0$ and $\beta_{i}=1$, therefore measuring the abnormal return as the difference between $R_{i t}$ and $R_{m t}$.
} 
capitalisation of the firm. Stocks added to the index are likely to have achieved relatively superior return performance immediately prior to being added, while the reverse is likely to be true for stocks deleted from the index. We therefore estimate the market model post event. 11

We calculate cumulative abnormal returns (CAR) from 10 days before the announcement date $(\mathrm{t}-17)$ to 20 days after the event date $(\mathrm{t}+20)$. These are obtained from the parameters of market models estimated over the period $t+21$ through to $t+$ 150. The requirement that we have at least 100 observations for the estimation of each market model reduces our sample to 65 additions and 65 deletions. The choice of a large window around the event is designed to reflect the possible impact of anticipatory trading prior to the announcement, i.e. it captures the limited ability of market participants to predict the changes announced by the Committee. Figure 1 gives the mean CAR for each day $(t-17$ to $t+20)$ for the additions, while Figure 2 gives the mean CAR for the deletions.

\section{Insert Figure 1}

\section{Insert Figure 2}

The cumulative abnormal return up to the announcement date $(\mathrm{t}-17$ to $\mathrm{t}-7)$ is $2.9 \%$ and $-4.8 \%$ for the additions and deletions respectively, while the corresponding abnormal return on the announcement date is just $0.3 \%$ and $-0.29 \%$. Over the whole preevent period ( $\mathrm{t}-17$ to $\mathrm{t}-1)$ the CAR are $4.7 \%$ and $-7.6 \%$. The event date sees the start of a reversal in the CAR, which by $\mathrm{t}+20$ are $-0.5 \%$ and $-2.4 \%$. In addition to this overall pattern, there is some indication of a smaller price reversal during the three days after the announcement ( $\mathrm{t}-6$ to $\mathrm{t}-4)$. The mean cumulative abnormal return for both additions

\footnotetext{
${ }^{11}$ See, for example, Kadlec and McConnell (1994), Brown et al. (1995) and Amihud et al. (1997).
} 
and deletions suggests there may be anticipatory trading prior to the announcement date $(\mathrm{t}-7)$. Given that the announcement is conditional on the stock's pre-announcement relative return performance, the pre-announcement CAR may also be due to a real price movement rather than the impending announcement. There is, however, some evidence that the pre-announcement price effects may be driven by the impending announcement, particularly for the additions. First, the price reversal during the three days after the announcement would be consistent with such short-term trading effects. Second, the return reversal over the complete event window $(t-17$ to $t+20)$ suggests that traders may be attempting to anticipate the announcement. Price effects that are driven by a temporary period of high demand will be subsequently reversed, and are consistent with the price pressure hypothesis. Such a price reversal begins at the event date, and is completed fully within two weeks. The pattern for the deletions is broadly similar, except that the price reversals are more limited. This would imply that while a portion of the pre-event price effects is driven by temporary price pressure, there is a portion that may be permanent. Again, the price reversal is effected within two weeks of the event date.

Standard event study methodology assumes that the event windows do not overlap, thereby ensuring that the abnormal returns calculated above are uncorrelated. Our events exhibit clustering, with up to six additions or deletions occurring simultaneously. As a result, we are unable to use the distribution of the individual firm CARs about the mean to determine the statistical significance of the mean CARs illustrated in Figures 1 and 2. We therefore use the methodology outlined in Thompson (1985) and applied more recently by Amihud et al. (1997). As Thompson (1985) notes, where 'the event periods are different across firms, the disturbances within event periods are generally uncorrelated across firms.' Alternatively, where the event periods are the same for some firms, i.e. there is event clustering, model parameters and associated variances should be estimated by aggregating the shared-event firm returns into 
portfolios. For each event cluster, we therefore calculate an equally weighted portfolio return. This procedure yields 23 portfolio returns for both the additions and deletions. ${ }^{12}$ Treating these portfolio returns as independent events, we estimate the following model over the period $\mathrm{t}-17$ through $\mathrm{t}+150$

$$
\mathrm{R}_{\mathrm{it}}=\alpha_{\mathrm{i}}+\beta_{\mathrm{i}} \mathrm{R}_{\mathrm{mt}}+\sum_{\mathrm{j}=1}^{4} \gamma_{\mathrm{ij}} \mathrm{D}_{\mathrm{ijt}}+\varepsilon_{\mathrm{it}}
$$

where $\mathrm{R}_{\mathrm{it}}$ and $\mathrm{R}_{\mathrm{mt}}$ are the returns to portfolio $\mathrm{i}$ and the market on day $\mathrm{t}$.

$D_{i 1 t}$ is a dummy variable with the value $1 / 11$ for the event days $t-17$ to $t-7$ (the announcement date), and 0 otherwise.

$D_{i 2 t}$ is a dummy variable with the value $1 / 3$ for the event days $t-6$ to $t-4$, and 0 otherwise.

$D_{i 3 t}$ is a dummy variable with the value $1 / 3$ for the event days $t-3$ to $t-1$, and 0 otherwise.

$D_{i 4 t}$ is a dummy variable with the value $1 / 21$ for the event days $t$ (the event date) to $\mathrm{t}+20$, and 0 otherwise.

These four dummy variables capture the abnormal returns over different periods within the event window. $\gamma_{i 1}$ represents the cumulative abnormal return to portfolio $i$ during the pre-announcement period, while the second and third dummies capture the price effects between the announcement and event dates. $\gamma_{\mathrm{i} 4}$ represents the post-event cumulative abnormal return. There is no theoretical justification for the use of two separate dummy variables between the announcement and the event. Our justification for including them is the patterns present in Figures 1 and 2. Further analysis of these patterns may increase our understanding of the trading that takes place around the announcement. They are also a direct benefit of the uniform six-day window between announcement and event dates in our data. We therefore also estimate the above model

\footnotetext{
${ }^{12}$ Five quarterly rankings occur without changes being made to the index constituents.
} 
with a single dummy variable, $\mathrm{D}_{\mathrm{i} 23 \mathrm{t}}$, replacing the two dummies $\mathrm{D}_{\mathrm{i} 2 \mathrm{t}}$ and $\mathrm{D}_{\mathrm{i} 3 \mathrm{t}}$. This single dummy captures the total price effect between announcement and event dates.

$D_{i 23 t}$ is a dummy variable with the value $1 / 6$ for the event days $t-6$ to $t-1$, and 0 otherwise.

We then calculate the mean dummy coefficient across each event, denoted $\mathrm{M} \gamma_{1} \ldots$ $\mathrm{M} \gamma_{4}$. Table II presents these, together with their associated t-statistics in parentheses,

$$
\mathrm{t}=\mathrm{M} \gamma_{\mathrm{j}} / \mathrm{SE}\left(\gamma_{\mathrm{j}}\right)
$$

where $\operatorname{SE}\left(\gamma_{\mathrm{j}}\right)$ is the cross-sectional standard error of the respective regression coefficients. The cumulative abnormal return across the pre-event window ( $\mathrm{t}-17$ to $\mathrm{t}-1)$ for each portfolio is simply the sum of $\gamma_{\mathrm{i} 1}+\gamma_{\mathrm{i} 2}+\gamma_{\mathrm{i} 3}$. The average of these is the mean cumulative abnormal return across the pre-event window (PEW). The sum of $\gamma_{i 2}+\gamma_{i 3}+\gamma_{i 4}$ represents the post-announcement (PA) abnormal return, while the sum of all four dummies enables us to calculate the mean cumulative abnormal return across the complete event window $t$ -17 to $t+20$, which we denote CEW. These are also reported in Table II along with the respective t-statistics. The robustness of the results in columns 2 and 4 are confirmed by the t-statistics $t\left(\gamma_{j}\right)$ reported in columns 3 and 5. These t-statistics are obtained from the $t-$ statistics of the individual model coefficients, i.e.

$$
t\left(\gamma_{j}\right)=\frac{\text { Mean of } t\left(\gamma_{i j}\right)}{\text { SD of } t\left(\gamma_{i j}\right) / \sqrt{N}}
$$

where $t\left(\gamma_{i j}\right)$ are the $t$-statistics from each of the individual model coefficients, and $\mathrm{N}$ is the number of addition or deletion portfolios. Both the above test statistics are asymptotically normal with mean zero. The test statistic, calculated as in (5), is the standard test statistic. It tests the null hypothesis that the mean abnormal return during each period within the event window is zero. The test statistic, calculated as in (6), tests the null that the weighted abnormal return is zero, where the weights are the inverses of the respective 
standard errors. This second statistic, by incorporating the estimated disturbance standard deviations, places less weight on those events where the coefficient was estimated with error.

\section{Insert Table II}

The results in Table II confirm the implications of the CAR plotted in Figures 1 and 2. For the additions, we find significantly positive mean CARs up to the announcement date $(\mathrm{t}-7)$ and between the announcement and event dates. Within this latter period there is a small but significant reversal during the three days after the announcement, before another significantly positive mean CAR from $t-3$ through to $t$ 1. Together, this yields a highly significant pre-event CAR of $4.7 \%$. The negative and significant CAR from $t$ through to $t+20$ represents a complete reversal of the pre-event positive abnormal return. Overall this yields a complete event window mean return ( $\mathrm{t}$ 17 to $t+20$ ) that is insignificantly different from zero.

The pattern for the deletions is the reverse. While the significantly negative CAR between announcement and event dates is driven by the return performance immediately prior to the event ( $\mathrm{t}-3$ to $\mathrm{t}-1)$, there is no evidence of a short-term reversal during the three days after the announcement. The mean pre-event window CAR is a highly significant $-7.6 \%$. This is followed by a post-event mean CAR of $5.2 \%$, which again produces an insignificant (although negative) mean abnormal return over the complete event window.

These results indicate highly significant positive (negative) mean cumulative abnormal returns prior to both the announcement date and event date of the addition (deletion) of a stock to (from) the FTSE 100. This contrasts with the findings of Lynch

\footnotetext{
${ }^{13}$ See Malatesta (1986).
} 
and Mendenhall (1997) for the S\&P 500. Their pre-announcement CARs are negative for the added firms and positive for the deleted firms. They also find large and significant positive (negative) abnormal returns on the announcement date for additions (deletions). It is possible that our pre-announcement CARs are a feature of the method used to determine index constituents in the UK. Ranking stocks on the basis of stock market capitalisation may naturally induce the pre-announcement price effects reported above. Alternatively, the pre-announcement price effects may indicate anticipatory trading prior to the announcement, particularly given the absence of an announcement day effect. In contrast to Lynch and Mendenhall (1997), the negligible abnormal return on the respective announcement days implies that the market is not surprised by the announcement, and may therefore have incorporated any announcement effect into prior returns. This possibility is further reinforced by the short-term reversal for additions immediately after the announcement date. The absence of such a reversal in deletions suggests that pre-announcement anticipatory trading may be less prevalent among these stocks.

Finally, Lynch and Mendenhall (1997) find only a partial reversal of pre-event CARs. The absence of significant abnormal returns over the complete event window in our data is evidence that the pre-event abnormal returns are fully reversed after the change takes place. If the pre-announcement price effects were real, rather than as a result of the impending announcement, then a reversal after the event should be less likely. The lack of a permanent price effect suggests that traders trade in anticipation of the changes that are likely to be announced. Overall, the pre-event returns appear to be induced by short-term buying (selling) pressure, indicative of a market that is unable to accommodate temporary changes in demand associated with changing the constituents of the FTSE 100. 


\subsection{Market Liquidity}

In order to consider the trading behaviour that might motivate the above results, we examine stock liquidity around the event. We use trading volume as a proxy for stock liquidity. Our measure of volume $\left(\mathrm{V}_{\mathrm{it}}\right)$ is that used by Lynch and Mendenhall (1997), and is equivalent to the value of shares traded (VAL) standardised by the value of shares outstanding (NOSH). Standardising by market value is designed to accommodate the possibility that volume (in terms of the number of shares traded) is likely to be positively related to stock market capitalisation. ${ }^{14}$ Following Ajinkya and Jain (1989), these are logtransformed to produce a measure that is closer to a normal distribution

$$
\mathrm{V}_{\mathrm{it}}=\frac{\log \left(\mathrm{VAL}_{\mathrm{it}}\right)}{\log \left(\mathrm{NOSH}_{\mathrm{it}}\right)}
$$

We use a similar technique to determine abnormal volume as for the analysis of returns above. We calculate abnormal volume from 10 days before the announcement $(\mathrm{t}$ 17) to 20 days after the event date $(t+20)$. A market model in volume gives abnormal volume for each firm

$$
\mathrm{V}_{\mathrm{it}}=\alpha_{\mathrm{i}}+\beta_{\mathrm{i}} \mathrm{V}_{\mathrm{mt}}+\varepsilon_{\mathrm{it}}
$$

where $V_{i t}$ and $V_{m t}$ are daily volume for security $i$ and the market. ${ }_{\text {Rather than estimate }}$ the parameters of the individual models over the period $t+21$ through to $t+150$ (as above), here we assume that pre-change volume represents the best measure of normal volume. We therefore estimate the model's parameters over the period t - 147 to $\mathrm{t}-18$. Figures 3 and 4 give the mean daily abnormal volume around the event for the additions and deletions respectively.

\footnotetext{
${ }^{14}$ This standardisation ensures that fluctuations in volume resulting from changes in prices (or market capitalisation) does not impact on our estimate of abnormal volume through the event window.

${ }^{15}$ See, for example, Lynch and Mendenhall (1997).
} 


\section{Insert Figure 3}

\section{Insert Figure 4}

There is an abnormal level of trading volume, and therefore market liquidity, around the event. This increased liquidity appears to be more marked for the additions. There is a consistent level of increased trading both prior to the announcement and the event for the additions, whereas there is increased trading only prior to the event for the deletions. Abnormal volume is greatest on the day prior to the event, being approximately $5.7 \%$ and $4.6 \%$ for the additions and deletions respectively. This abnormal volume coincides with respective abnormal returns on day $\mathrm{t}-1$ of $2 \%$ and $-2.2 \%$. The positive abnormal volume occurs earlier for the additions. The abnormal volume prior to the announcement date for the additions is consistent with the anticipatory trading reported above in respect of the pre-announcement abnormal returns. The pattern of abnormal volume for the deletions is more straightforward, with increased volume occurring immediately before the event followed by subdued trading after the event. As before, we are unable to determine the statistical significance of the abnormal volume because of event clustering. We therefore compute the mean trading volume for each event cluster, each cluster then being treated as a separate event. The following model is estimated over the period $\mathrm{t}-147$ through $\mathrm{t}+20$

$$
\mathrm{V}_{\mathrm{it}}=\alpha_{\mathrm{i}}+\beta_{\mathrm{i}} \mathrm{V}_{\mathrm{mt}}+\sum_{\mathrm{j}=1}^{4} \gamma_{\mathrm{ij}} \mathrm{D}_{\mathrm{ijt}}+\varepsilon_{\mathrm{it}}
$$

where $\mathrm{V}_{\mathrm{it}}$ is the mean trading volume for event cluster $\mathrm{i}$ on day $\mathrm{t}$, and $\mathrm{V}_{\mathrm{mt}}$ is the market trading volume on day $\mathrm{t}$. The five dummies $\left(\mathrm{D}_{\mathrm{ij}}\right)$ and associated $\mathrm{t}$-statistics are as before, and represent the mean and significance of the cumulative abnormal trading volume (CAV) measured over various event windows. 
The results from Table III indicate significantly positive abnormal volume over the pre-event window (PEW) for both the additions and the deletions. When measured over the complete event window (CEW), this increased trading persists for the additions, although there is no evidence of significantly increased trading after the event for either sample $\left(\mathrm{M} \gamma_{4}\right)$. Within this pattern of overall increased trading volume, an important difference between the two samples is the significantly positive abnormal volume prior to the announcement for stocks added to the index $\left(\mathrm{M} \gamma_{1}\right)$. Abnormal volume between the announcement and event dates $\left(\mathrm{M} \gamma_{23}\right)$ is almost identical.

These findings reveal a significant increase in stock liquidity around the period of FTSE 100 constituent changes. There is, however, no evidence of a significant increase in liquidity once the changes have been made, suggesting that being a constituent of the index may not have a significant impact on a stock's liquidity. The general pattern in trading volume through the event period is consistent with the pattern observed in the CARs. Trading volume is greatest during the three days immediately prior to the event date $\left(\mathrm{M} \gamma_{3}\right)$, consistent with short-term buying (selling) pressure. This pressure is strongest on the day prior to the event date, possibly reflecting the rebalancing trades of index trackers.

The nature of the changes made to the FTSE 100, occurring as part of a regular series of quarterly reviews, should enable traders to anticipate the announcement. We find strong evidence of increased trading prior to the announcement only for additions. If this trading increase were due to the impending announcement, then it would suggest that traders attempt to anticipate the additions and not the deletions. Such pre-announcement anticipatory trading would be consistent with the post-announcement return reversal noted above. 
The asymmetry in pre-announcement volume between additions and deletions implies that index trackers might not be the cause of the anticipatory trading prior to the announcement. Index trackers should be equally able to buy additions or sell deletions, given that they will already hold the stocks to be deleted. The pre-announcement CARs indicate that pre-announcement trading in the deletions would be as profitable as preannouncement trading in the additions. If index trackers trade prior to the announcement, then we would expect to observe a more symmetrical pattern in trading volume for the two samples. On the other hand, other non-index-tracking investors able to anticipate the announcement will be more inclined to buy an expected addition (in the expectation of a price appreciation), than short sell an expected deletion because of the costs and constraints associated with short selling. ${ }^{16}$ The absence of increased trading activity immediately after the additions announcement suggests that the non-index-tracking traders who traded in anticipation of the announcement do not reverse their trades until just before the event date. If this is the case, then it would be consistent with the most profitable trading strategy implied by Figure 1.

\section{4 'Nearly' Stocks}

This section investigates trading around the quarterly review for those firms that just avoid being deleted from (or just fail to be promoted to) the FTSE 100 Index. As noted above, the nature of the rules concerning the organisation of the FTSE 100 means there will be some uncertainty regarding which stocks will be included or deleted until immediately before the announcement is made $e^{17}$. An examination of trading in the 'nearly out' and 'nearly in' stocks will help to reveal the extent to which traders may

\footnotetext{
${ }^{16}$ The most important constraint is that most funds, such as pension and mutual funds, cannot engage in short sales. Their mandate typically precludes them from such speculation.

${ }^{17}$ Unlike the S\&P 500, investors will know the precise timing of all forthcoming announcements.
} 
attempt to anticipate (with error) these announcements. In principle, the 'nearly' stocks should be unaffected by the announcements, since they are unaffected by the event itself, i.e. they do not enter or leave the index. Patterns in returns or trading volume around the quarterly review announcement dates would be of interest because they would demonstrate that traders are attempting to anticipate these announcements.

For each quarterly review, we determine the three smallest stocks remaining in the FTSE 100, and the three largest stocks remaining outside the FTSE 100. This yields 84 stocks for the 'nearly out' and 'nearly in' samples respectively. We then conduct a similar analysis to the inclusions and deletions. The daily abnormal returns and abnormal volumes (calculated using Eq. (3) and Eq. (8)), are smaller than observed above for the inclusions and deletions, so we do not present the plots of CARs and AVs. Instead we present the results for the event clusters only. For each quarterly review, we calculate an equally weighted portfolio return and trading volume. We then estimate Eq. (4) and Eq. (9) for the respective 28 event portfolios. The results are presented in Tables IV and V. We estimate the same dummy variables as before to ease comparison. Given that for these stocks there is no event, we do not aggregate the dummies to calculate a pre-event window return or trading volume.

\section{Insert Table IV}

\section{Insert Table V}

The magnitudes of the abnormal returns and trading volumes are clearly less than those obtained for the additions and deletions. Prior to the announcement, for example, the mean CAR is $-1.2 \%$ and $1.7 \%$ for the 'nearly out' and 'nearly in' stocks respectively. While these are significant, they are smaller than the equivalent pre-announcement returns of $-4.8 \%$ and $2.9 \%$ for the deleted and included firms. It is interesting to note that once the announcement is made there is no evidence of significant non-zero returns. The 
post-announcement returns are an identical $-0.9 \%$. The respective pre-announcement return performances of the two samples may therefore have been influenced by the possibility of them being deleted from (included in) the FTSE 100.

The results in Table V contribute to this prospect. Overall, both samples record an increase in trading volume through the complete event window of just below $7 \%$. However, there is a marked contrast in the timing of this extra volume. We find significantly positive abnormal volume prior to the announcement among the stocks that just fail to be included in the index. For the 'nearly out' stocks, there is significantly positive volume immediately prior to the event date, and over the post-announcement window as a whole.

These results suggest strongly that trading may occur in anticipation of the announcement. Among the stocks that just fail to be included in the FTSE 100, we find significantly positive abnormal returns and trading volume immediately prior to the announcement date. While there is significant underperformance prior to the announcement among stocks that just avoid being deleted, there is no evidence of increased trading volume. This asymmetry indicates that anticipatory trading may occur among the 'nearly in' stocks, rather than among the 'nearly out' stocks, and is in line with the results for the additions and deletions above.

Finally, the finding that trading in the 'nearly out' stocks increases immediately prior to the date on which the associated changes are made is more difficult to explain. While the increased trading volume is consistent with that found for the deleted stocks, it cannot be directly related to the event itself. One possibility is that index trackers switch out of these stocks into the newly added stocks, since the newly added stocks will nearly

\footnotetext{
${ }^{18}$ It is also possible that these pre-announcement returns are due to selection bias, prior performance determining the ranking of the stocks.
} 
always have larger market capitalisations and therefore be relatively more important in terms of minimizing index tracking error. An alternative explanation is that the increased volume in the 'nearly out' stocks reflects portfolio rebalancing as a result of a change in index weights following the change in index constituents. We argue this is unlikely since a change in index weights will affect all the constituents, and therefore should lead to increased trading volume for the market as a whole. If this were the case we would not expect to find an increased level of trading volume since the abnormal volumes are obtained from estimates of a market model in volume (Eq. (9)).

\section{Conclusion}

This study examines the impact of changes in the FTSE 100 Index between 1992 and 1999. The analysis of long-run performance yields three-year buy-and-hold abnormal returns (measured from 21 days after the event date) of $20.93 \%$ following a stock's addition to the FTSE 100, and $-19.31 \%$ following a stock's deletion from the FTSE 100 . The matching procedure used controls for both size and industry effects, so we can only speculate that these long-run abnormal returns reflect the impact of increased (reduced) investor interest in additions (deletions), possibly as a result of index tracking.

The analysis of short-run returns and volume around the event indicates shortterm price pressure prior to changes in the constituents of the FTSE 100 Index, both for additions and deletions. In contrast to previous research in the US, there is no evidence of a permanent short-term price effect. The temporary nature of the abnormal returns during the pre-event window is consistent with a temporary change in demand, again possibly induced by traders attempting to track the index. The analysis of trading volume around the event reinforces the view that the pattern in abnormal returns is driven by short-term buying (or selling) pressure. The buying (selling) pressure induced by a change in index 
constituents is associated with an increase in trading volume, or stock liquidity, prior to the event date. The stabilisation of trading volume post-event coincides with the reversal in returns.

Interestingly, we find an asymmetry in the level of abnormal volume prior to the announcement. This asymmetry implies that trading in anticipation of the announcement occurs only for the additions. Consistent with this is the evidence of a short-term return reversal for the additions immediately after the announcement, in line with the easing of the pre-announcement buying pressure. The asymmetry indicates it is unlikely that index trackers attempt to pre-empt the announcement of changes to the index. If they were to do so, there seems no logical explanation why they would not do the same for the deletions. It is more likely that other traders are taking advantage of the requirement for index trackers to track the index. These other non-index-tracking investors will be able to buy the additions, but will be less able to short sell the deletions. The more uniform buying and selling immediately prior to the change date is consistent with index tracker trading.

The asymmetry in trading volume is also found in an analysis of 'nearly' stocks, those that just fail to be promoted to, or just avoid being deleted from, the FTSE 100. Trading volume is abnormally large prior to the announcement date for 'nearly in' stocks, suggesting that (as with the additions) some traders speculate on the announcement. Increased trading immediately prior to the change date for 'nearly out' stocks is more difficult to explain. We suggest that it may be due to index trackers switching out of these stocks and into the relatively larger newly added stocks. 


\section{References}

Ajinkya, B. and Jain, P. (1989), 'The Behaviour of Daily Stock Market Volume', Journal of Accounting and Economics 11, 331-360.

Amihud, Y. and Mendelson, H. (1986), 'Asset Pricing and the Bid-Ask Spread', Journal of Financial Economics 17, 223-249.

Amihud, Y., Mendelson, H. and Lauterbach, B. (1997), 'Market Microstructure and Security Values: Evidence from the Tel Aviv Stock Exchange', Journal of Financial Economics 45, 365-390.

Barber, B. and Lyon, J. (1997), 'Detecting Long-Run Abnormal Stock Returns: The Empirical Power and Specification of Test Statistics', Journal of Financial Economics 43, 341-372.

Beneish, M. and Gardner, J. (1995), 'Information Costs and Liquidity Effects from Changes in the Dow Jones Industrial Average List', Journal of Financial and Quantitative Analysis 30, 135-148.

Beneish, M. and Whaley, R. (1996), "An Anatomy of the "S\&P Game": The Effects of Changing the Rules', Journal of Finance 51, 1909-1930.

Berkman, H. and Eleswarapu, V. (1998), 'Short-Term Traders and Liquidity: A Test using Bombay Stock Exchange Data', Journal of Financial Economics 47, 339-355.

Brown, S., Goetzmann, W. and Ross, W. (1995), 'Survival', Journal of Finance 50, 853-873.

Desai, H. and Jain, P. (1999), 'Firm Performance and Focus: Long-run Stock Market Performance Following Spinoffs', Journal of Financial Economics 54, 75-101.

Dhillon, U. and Johnson, H. (1991), 'Changes in the Standard and Poor's 500 List', Journal of Business 64, 75-85.

Harris, L. and Gurel, E. (1986), 'Price and Volume Effects Associated with Changes in the S\&P 500 List: New Evidence for the Existence of Price Pressures', Journal of Finance 41, 815-829.

Jegadeesh, N., and Titman, S. (1993), 'Returns to Buying Winners and Selling Losers: Implications for Stock Market Efficiency', Journal of Finance 48, 65-91.

Kaul, A., Mehrotra, V. and Morck, R. (2000), 'Demand Curves for Stocks Do Slope Down: New Evidence From an Index Weights Adjustment', Journal of Finance 55, 893-912.

Kothari, S. and Warner, J. (1997), 'Measuring Long-Horizon Security Price Performance', Journal of Financial Economics 43, 301-339. 
Lynch, A. and Mendenhall, R. (1997), 'New Evidence of Stock Price Effects Associated with Changes in the S\&P 500 Index', Journal of Business 70, 351-383.

Lyon, J., Barber, B. and Tsai, C-L. (1999), 'Improved Methods for Tests of Long-Run Abnormal Stock Returns', Journal of Finance 54, 165-201.

Malatesta, P. (1986), 'Measuring Abnormal Performance: The Event Parameter Approach using Joint Generalized Least Squares', Journal of Financial and Quantitative Analysis 20, 27-38.

Pruitt, and Wei, (1989), 'Institutional Ownership and Changes in the S\&P 500', Financial Analysts Journal 43, 58-65.

Rouwenhorst, G. (1998), 'International Momentum Strategies', Journal of Finance 53, 267-284.

Scholes, M. (1972), 'The Market for Securities: Substitution vs. Price Pressure and the Effect of Information on Share Prices', Journal of Business 45, 179-211.

Shleifer, A. (1986), 'Do Demand Curves for Stocks Slope Downward?’ Journal of Finance 41, 579-590.

Thompson, R. (1985), 'Conditioning the Return-Generating Process on Firm-Specific Events: A Discussion of Event Study Methods', Journal of Financial and Quantitative Analysis 20, 151168.

Vijh, A. (1999), 'Long-term Returns from Equity Carveouts', Journal of Financial Economics 51, 273 308. 
Table I Long-run abnormal stock returns of additions to (and deletions from) the FTSE 100 Index, 1992 - 1999.

\begin{tabular}{ccccc}
\hline & \multicolumn{2}{c}{ Additions } & \multicolumn{2}{c}{ Deletions } \\
\hline & $\begin{array}{c}\text { One-Year } \\
\text { BHAR }\end{array}$ & $\begin{array}{c}\text { Three-Year } \\
\text { BHAR }\end{array}$ & $\begin{array}{c}\text { One-Year } \\
\text { BHAR }\end{array}$ & $\begin{array}{c}\text { Three-Year } \\
\text { BHAR }\end{array}$ \\
AD & $10.77^{*}$ & $17.61^{*}$ & -5.00 & -16.41 \\
ED +21 & $12.14^{*}$ & $20.93^{*}$ & -7.54 & $-19.31^{*}$ \\
\hline
\end{tabular}

Columns 2 through 5 give the mean (\%) one and three-year buy-and-hold abnormal returns (BHAR) for additions to, and deletions from, the FTSE 100 Index. The buy-and-hold abnormal returns over the period $\tau$ for each sample firm are measured as $B H A R_{i \tau}=\Pi_{t=1}^{\tau}\left[1+R_{i t}\right]-\Pi_{t=1}^{\tau}\left[1+R_{j t}\right]$, where $R_{i t}$ is the buy-and-hold return to the sample firm $i$ and $R_{j t}$ is the buy-and-hold return to its matching firm $j$. Firms are matched on the basis of industry classification and market value. AD returns are estimated from the announcement date $(\mathrm{t}-7), \mathrm{ED}+21$ are estimated from 21 days after the event date $(\mathrm{t}+21)$. $*$ denotes significance at the $1 \%$ level, obtained from the bootstrapped application of the skewness-adjusted tstatistic; $\mathrm{t}_{\mathrm{sa}}=\sqrt{\mathrm{n}}\left(\mathrm{S}+\frac{\hat{\gamma} \mathrm{S}^{2}}{3}+\frac{\hat{\gamma}}{6 \mathrm{n}}\right)$, where $\mathrm{S}=\frac{\overline{\mathrm{BHAR}}_{\tau}}{\sigma\left(\mathrm{BHAR}_{\tau}\right)}$, and $\hat{\gamma}=\frac{\sum_{\mathrm{i}=1}^{\mathrm{n}}\left(\mathrm{BHAR}_{\mathrm{i} \tau}-\overline{\mathrm{BHAR}}_{\tau}\right)^{3}}{\mathrm{n} \sigma\left(\mathrm{BHAR}_{\tau}\right)^{3}}$. 
Figure 1 Cumulative abnormal returns around the announcement and event dates of additions to the FTSE 100 Index

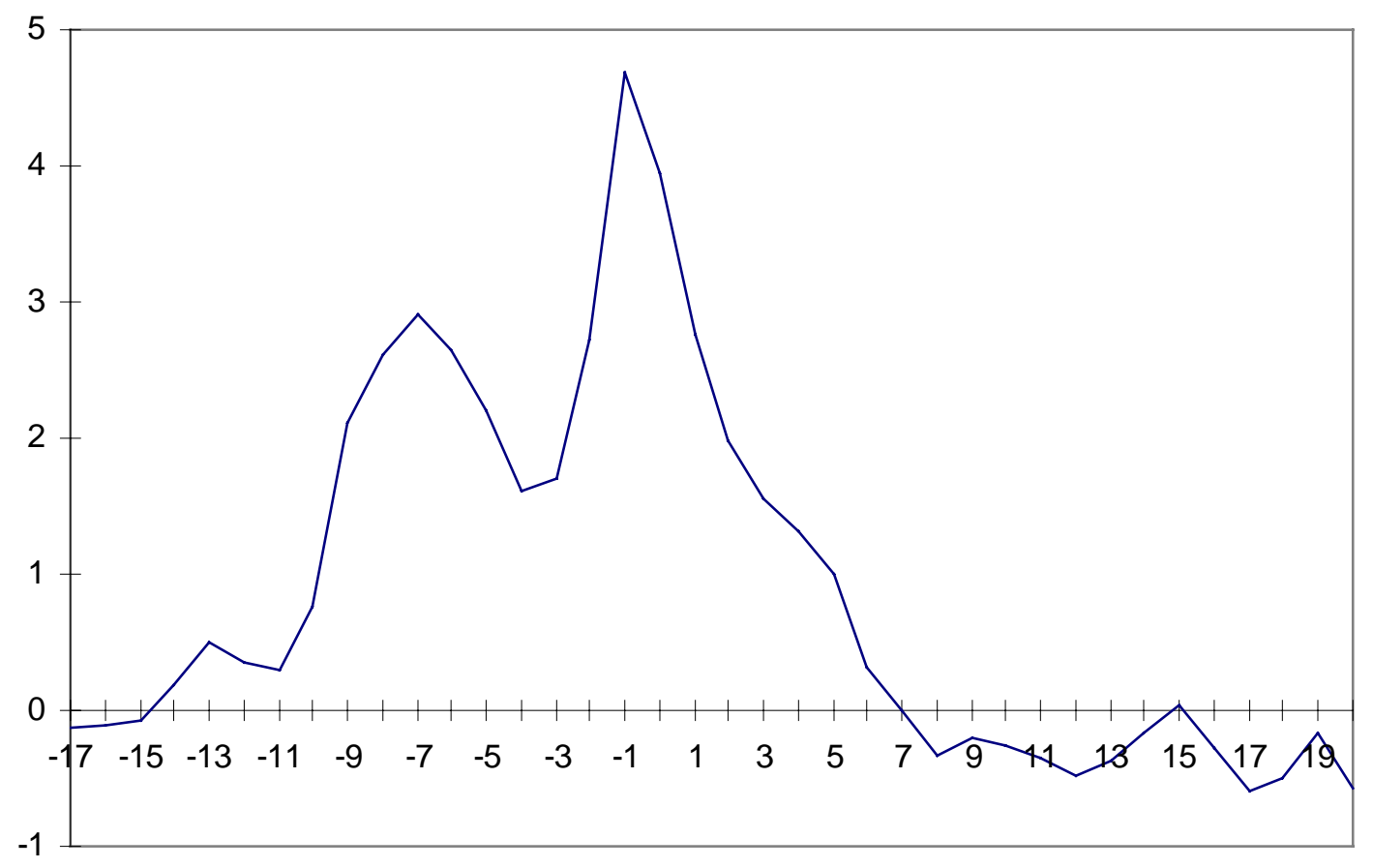

Fig. 1 gives the mean cumulative abnormal return (\%) for stocks added to the FTSE 100 Index between $1 / 4 / 92$ and $1 / 4 / 99$. The announcement date is -7 , the event date is 0 . The CAR are obtained from the market model $R_{i t}=\alpha_{i}+\beta_{i} R_{m t}+\varepsilon_{i t}$ estimated over the period $t+21$ to $t+150$, where $R_{i t}$ and $R_{m t}$ are the returns to security $i$ and the market on day $t$. 
Figure 2 Cumulative abnormal returns around the announcement and event dates of deletions from the FTSE 100 Index

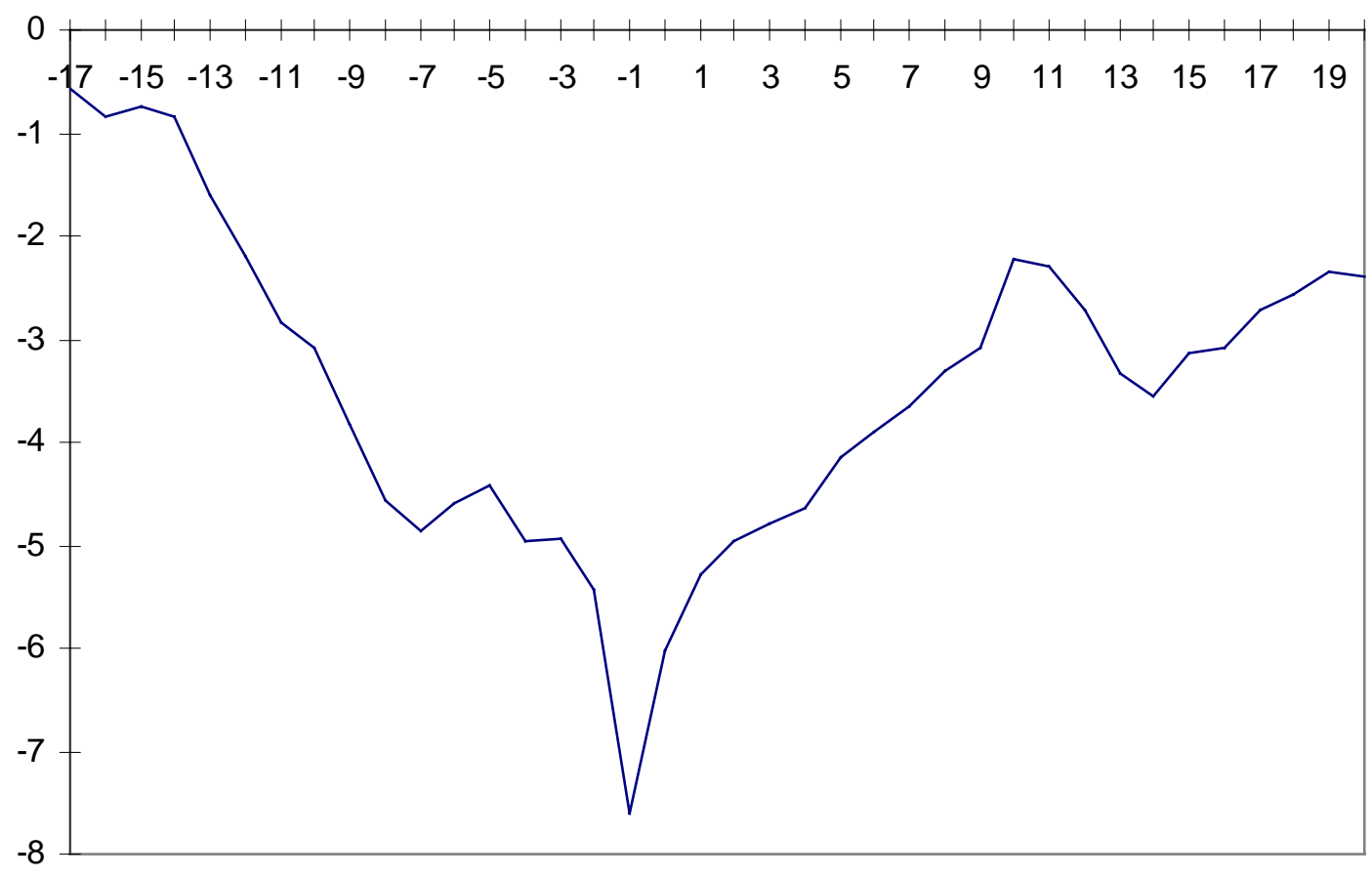

Fig. 2 gives the mean cumulative abnormal return (\%) for stocks deleted from the FTSE 100 Index between $1 / 4 / 92$ and $1 / 4 / 99$. The announcement date is -7 , the event date is 0 . The CAR are obtained from the market model $R_{i t}=\alpha_{i}+\beta_{i} R_{m t}+\varepsilon_{i t}$ estimated over the period $t+21$ to $t+150$, where $R_{i t}$ and $R_{m t}$ are the returns to security $i$ and the market on day $t$. 
Table II Price effects around the announcement and event dates of additions to (and deletions from) the FTSE 100 Index

\begin{tabular}{|c|c|c|c|c|}
\hline & Additions & & Deletion & \\
\hline & & $\mathrm{t}\left(\gamma_{\mathrm{j}}\right)$ & & $\mathrm{t}\left(\gamma_{\mathrm{j}}\right)$ \\
\hline$\alpha$ & $\begin{array}{l}0.0018 \\
(2.37)\end{array}$ & 2.50 & $\begin{array}{l}0.0011 \\
(1.06)\end{array}$ & 0.46 \\
\hline$\beta$ & $\begin{array}{l}0.868 \\
(16.07)\end{array}$ & 15.33 & $\begin{array}{l}0.677 \\
(12.36)\end{array}$ & 11.32 \\
\hline $\mathrm{M} \gamma_{1}$ & $\begin{array}{l}0.029 \\
(3.74)\end{array}$ & 3.64 & $\begin{array}{l}-0.048 \\
(-5.11)\end{array}$ & -5.41 \\
\hline $\mathrm{M} \gamma_{2}$ & $\begin{array}{l}-0.013 \\
(-2.53)\end{array}$ & -2.68 & $\begin{array}{l}-0.002 \\
(-0.26)\end{array}$ & -0.39 \\
\hline $\mathrm{M} \gamma_{3}$ & $\begin{array}{l}0.030 \\
(4.83)\end{array}$ & 5.58 & $\begin{array}{l}-0.026 \\
(-4.13)\end{array}$ & -5.56 \\
\hline $\mathrm{M} \gamma_{4}$ & $\begin{array}{l}-0.052 \\
(-3.84)\end{array}$ & -3.92 & $\begin{array}{l}0.052 \\
(2.76)\end{array}$ & 3.21 \\
\hline $\mathrm{M} \gamma_{23}$ & $\begin{array}{l}0.017 \\
(2.79)\end{array}$ & 2.84 & $\begin{array}{l}-0.028 \\
(-3.00)\end{array}$ & -3.16 \\
\hline PA & $\begin{array}{l}-0.035 \\
-2.69\end{array}$ & & $\begin{array}{l}0.024 \\
1.17\end{array}$ & \\
\hline PEW & $\begin{array}{l}0.047 \\
(4.41)\end{array}$ & & $\begin{array}{l}-0.076 \\
(-6.57)\end{array}$ & \\
\hline CEW & $\begin{array}{l}-0.005 \\
(-0.32)\end{array}$ & & $\begin{array}{l}-0.024 \\
(-1.15)\end{array}$ & \\
\hline
\end{tabular}

Columns 2 and 4 give the mean cumulative abnormal returns around the announcement and event dates for additions to, and deletions from, the FTSE 100 Index. The CAR are obtained from the model $\mathrm{R}_{\mathrm{it}}=\alpha_{\mathrm{i}}+\beta_{\mathrm{i}} \mathrm{R}_{\mathrm{mt}}+\sum_{\mathrm{j}=1}^{4} \gamma_{\mathrm{ij}} \mathrm{D}_{\mathrm{ijt}}+\varepsilon_{\mathrm{it}}$ estimated over the period $\mathrm{t}-17$ to $\mathrm{t}+150$, where $\mathrm{R}_{\mathrm{it}}$ is the equally weighted return to event portfolio $\mathrm{i}$, and $\mathrm{R}_{\mathrm{mt}}$ is the return to the market, on day $\mathrm{t}$. The mean of the four dummy coefficients $M \gamma 1 \ldots M \gamma 4$ represent the mean cumulative abnormal return across days $t-17$ to $t-7, t$ - 6 to $\mathrm{t}-4, \mathrm{t}-3$ to $\mathrm{t}-1$ and $\mathrm{t}$ to $\mathrm{t}+20$. M $\gamma_{23}$ is the mean cumulative abnormal return across days $\mathrm{t}-6$ to $\mathrm{t}$ 1. Associated t-statistics are in parentheses, $t=M \gamma_{j} / \operatorname{SE}\left(\gamma_{j}\right)$, where $\operatorname{SE}\left(\gamma_{j}\right)$ is the cross-sectional standard error of the respective regression coefficients. PEW and CEW represent the mean cumulative abnormal return across the pre-event window ( $t-17$ to $t-1)$ and the complete event window $(t-17$ to $t+20)$. PA represents the post-announcement mean cumulative abnormal return ( $t-6$ to $t+20)$. Columns 3 and 5 give $t$-statistics for tests of the significance of the estimated t-statistics, where $t\left(\gamma_{j}\right)=\frac{\text { Meanof } t\left(\gamma_{i j}\right)}{\operatorname{SDof} t\left(\gamma_{i j}\right) / \sqrt{N}}$. 
Figure 3 Abnormal volume around the announcement and event dates of additions to the FTSE 100 Index

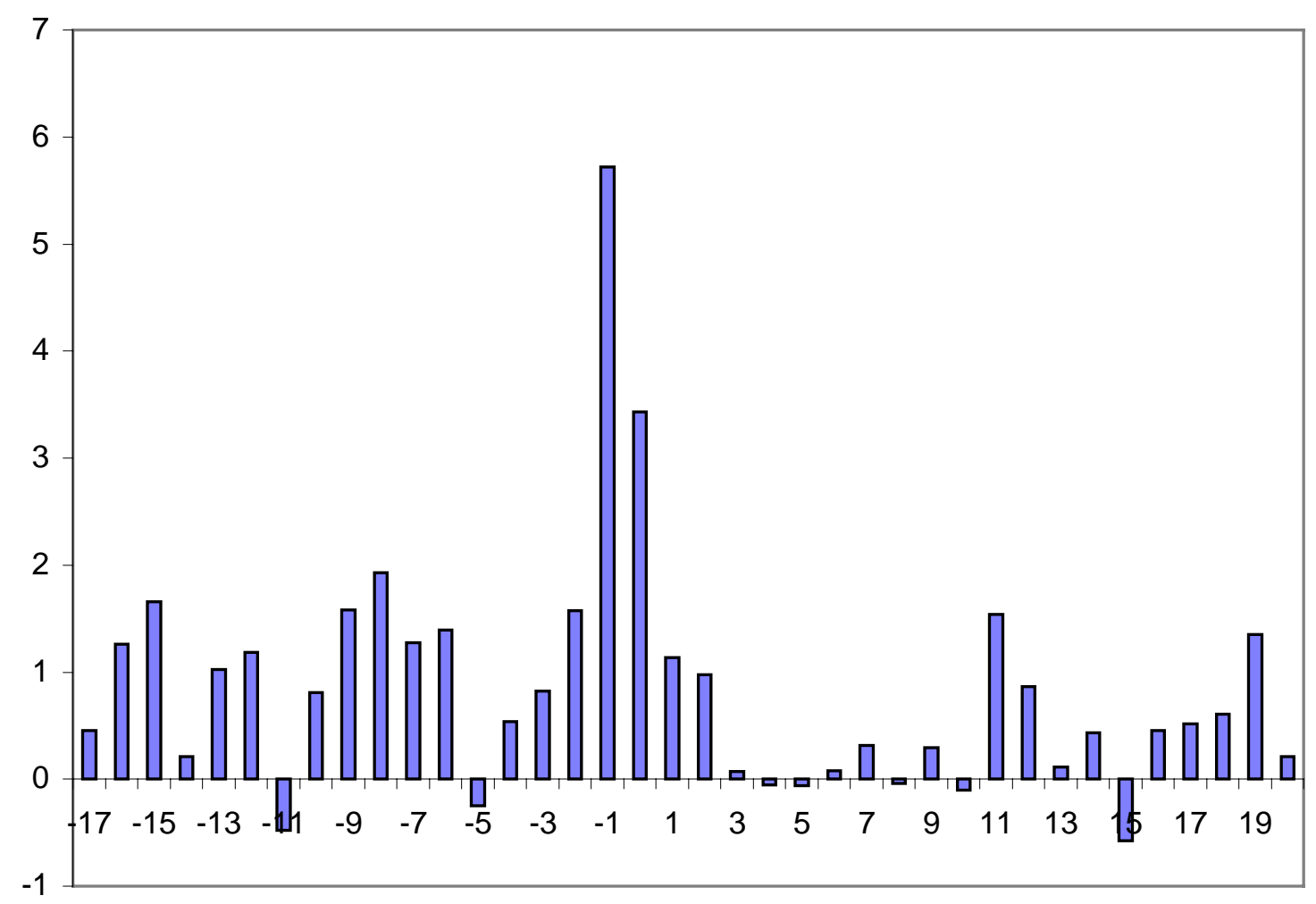

Fig. 3 gives the mean abnormal volume (\%) for stocks added to the FTSE 100 Index between 1/4/92 and $1 / 10 / 98$. The announcement date is -7 , the event date is 0 . The AV are obtained from the market model $\mathrm{V}_{\mathrm{it}}=\alpha_{\mathrm{i}}+\beta_{\mathrm{i}} \mathrm{V}_{\mathrm{mt}}+\varepsilon_{\mathrm{it}}$ estimated over the period $\mathrm{t}-147$ to $\mathrm{t}-18$, where $\mathrm{V}_{\mathrm{it}}$ and $\mathrm{V}_{\mathrm{mt}}$ are daily volume for security $i$ and the market. Volume is the logarithm of the value of shares traded divided by the logarithm of the value of shares outstanding. 
Figure 4 Abnormal volume around the announcement and event dates of deletions from the FTSE 100 Index

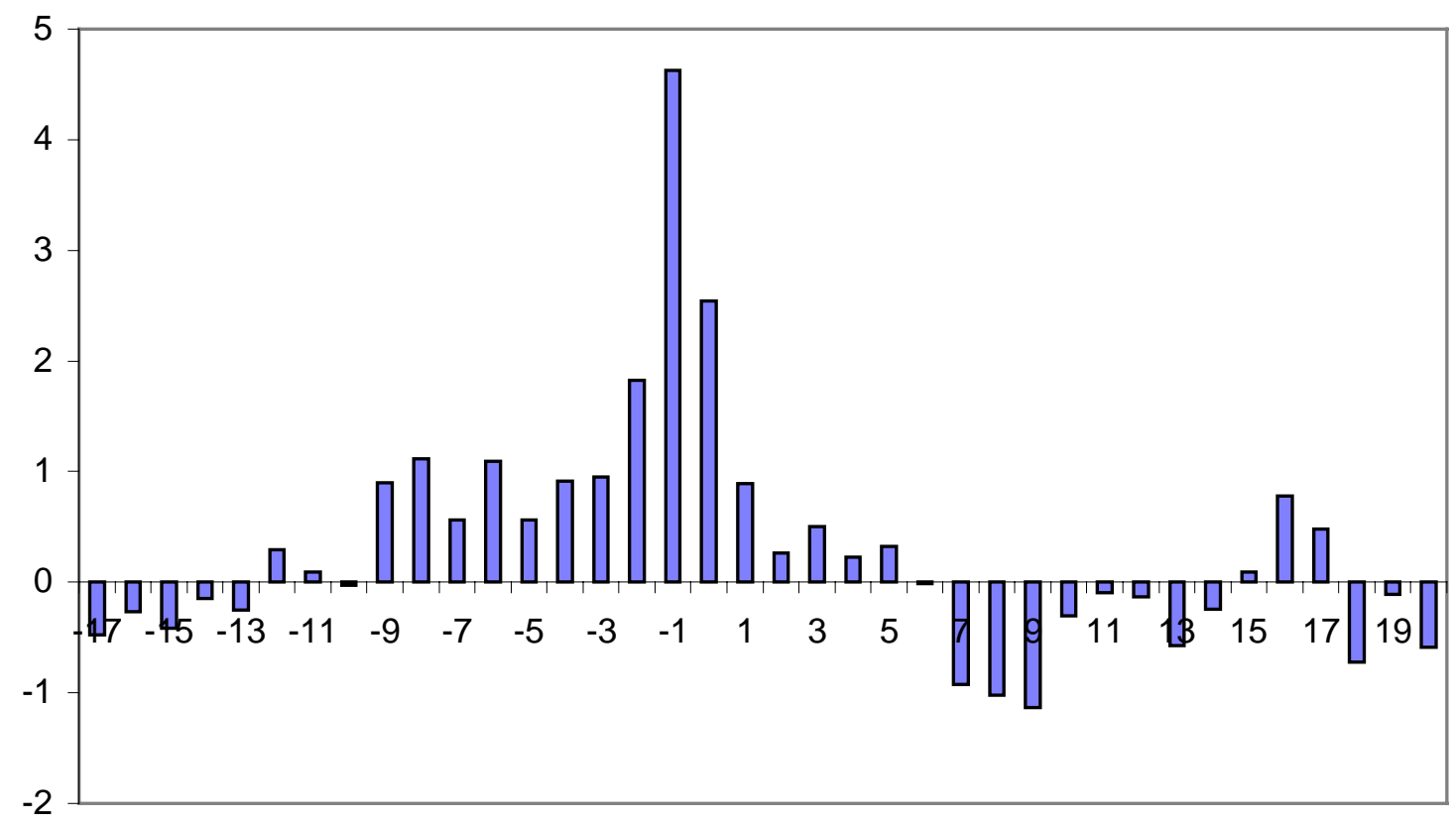

Fig. 4 gives the mean abnormal volume (\%) for stocks deleted from the FTSE 100 Index between 1/4/92 and $1 / 4 / 99$. The announcement date is -7 , the event date is 0 . The AV are obtained from the market model $\mathrm{V}_{\mathrm{it}}=\alpha_{\mathrm{i}}+\beta_{\mathrm{i}} \mathrm{V}_{\mathrm{mt}}+\varepsilon_{\mathrm{it}}$ estimated over the period $\mathrm{t}-147$ to $\mathrm{t}-18$, where $\mathrm{V}_{\mathrm{it}}$ and $\mathrm{V}_{\mathrm{mt}}$ are daily volume for security $i$ and the market. Volume is the logarithm of the value of shares traded divided by the logarithm of the value of shares outstanding. 
Table III Liquidity effects around the announcement and event dates of additions to (and deletions from) the FTSE 100 Index

\begin{tabular}{|c|c|c|c|c|}
\hline & Additions & & Deletion & \\
\hline & & $\mathrm{t}\left(\gamma_{\mathrm{j}}\right)$ & & $\mathrm{t}\left(\gamma_{\mathrm{j}}\right)$ \\
\hline$\alpha$ & $\begin{array}{l}-0.098 \\
(-1.98)\end{array}$ & -2.59 & $\begin{array}{l}-0.242 \\
(-5.59)\end{array}$ & -5.46 \\
\hline$\beta$ & $\begin{array}{l}1.060 \\
(16.16)\end{array}$ & 9.71 & $\begin{array}{l}1.238 \\
(21.55)\end{array}$ & 15.97 \\
\hline $\mathrm{M} \gamma_{1}$ & $\begin{array}{l}0.107 \\
(2.86)\end{array}$ & 2.77 & $\begin{array}{l}.012 \\
(0.44)\end{array}$ & 0.37 \\
\hline $\mathrm{M} \gamma_{2}$ & $\begin{array}{l}.016 \\
(1.21)\end{array}$ & 0.58 & $\begin{array}{l}.025 \\
(1.94)\end{array}$ & 1.57 \\
\hline $\mathrm{M} \gamma_{3}$ & $\begin{array}{l}.079 \\
(4.92)\end{array}$ & 4.29 & $\begin{array}{l}.074 \\
(7.57)\end{array}$ & 7.37 \\
\hline $\mathrm{M} \gamma_{4}$ & $\begin{array}{l}.111 \\
(1.90)\end{array}$ & 1.85 & $\begin{array}{l}.004 \\
(0.08)\end{array}$ & 0.02 \\
\hline $\mathrm{M} \gamma_{23}$ & $\begin{array}{l}0.095 \\
(3.98)\end{array}$ & 3.96 & $\begin{array}{l}0.096 \\
(4.98)\end{array}$ & 5.22 \\
\hline PA & $\begin{array}{l}0.207 \\
2.74\end{array}$ & & $\begin{array}{l}0.104 \\
1.55\end{array}$ & \\
\hline PEW & $\begin{array}{l}.202 \\
(3.59)\end{array}$ & & $\begin{array}{l}.112 \\
(2.82)\end{array}$ & \\
\hline CEW & $\begin{array}{l}.313 \\
(3.00)\end{array}$ & & $\begin{array}{l}.116 \\
(1.47)\end{array}$ & \\
\hline
\end{tabular}

Columns 2 and 4 give the mean cumulative abnormal volume around the announcement and event dates for additions to, and deletions from, the FTSE 100 Index. The CAV are obtained from the model $\mathrm{V}_{\mathrm{it}}=\alpha_{\mathrm{i}}+\beta_{\mathrm{i}} \mathrm{V}_{\mathrm{mt}}+\sum_{\mathrm{j}=1}^{4} \gamma_{\mathrm{ij}} \mathrm{D}_{\mathrm{ijt}}+\varepsilon_{\mathrm{it}}$ estimated over the period $\mathrm{t}-147$ to $\mathrm{t}+20$, where $\mathrm{V}_{\mathrm{it}}$ is the mean trading volume for event portfolio $\mathrm{i}$, and $\mathrm{V}_{\mathrm{mt}}$ is the volume to the market, on day $\mathrm{t}$. Volume is the logarithm of the value of shares traded divided by the logarithm of the value of shares outstanding. The mean of the four dummy coefficients $\mathrm{M} \gamma 1 \ldots \mathrm{M} \gamma 4$ represent the mean cumulative abnormal volume across days $\mathrm{t}-17$ to $\mathrm{t}-7, \mathrm{t}-6$ to $\mathrm{t}-4, \mathrm{t}-3$ to $\mathrm{t}-1$ and $\mathrm{t}$ to $\mathrm{t}+20 . \mathrm{M} \gamma_{23}$ is the mean cumulative abnormal volume across days $\mathrm{t}-$ 6 to $\mathrm{t}-1$. Associated $\mathrm{t}$-statistics are in parentheses, $\mathrm{t}=\mathrm{M} \gamma_{\mathrm{j}} / \operatorname{SE}\left(\gamma_{\mathrm{j}}\right)$, where $\operatorname{SE}\left(\gamma_{\mathrm{j}}\right)$ is the cross-sectional standard error of the respective regression coefficients. PEW and CEW represent the mean cumulative abnormal volume across the pre-event window ( $\mathrm{t}-17$ to $\mathrm{t}-1)$ and the complete event window ( $\mathrm{t}-17$ to $\mathrm{t}+$ 20). PA represents the post-announcement mean cumulative abnormal volume $(t-6$ to $t+20)$. Columns 3 and 5 give t-statistics for tests of the significance of the estimated t-statistics, where $t\left(\gamma_{j}\right)=\frac{\text { Mean of } t\left(\gamma_{i j}\right)}{\operatorname{SD~of~} t\left(\gamma_{i j}\right) / \sqrt{N}}$ 
Table IV Price effects around the quarterly review for the 'nearly' firms

\begin{tabular}{|c|c|c|c|c|}
\hline & Nearly out & & Nearly in & \\
\hline & & $\mathrm{t}\left(\gamma_{\mathrm{j}}\right)$ & & $\mathrm{t}\left(\gamma_{\mathrm{j}}\right)$ \\
\hline$\alpha$ & $\begin{array}{l}0.0008 \\
(0.02)\end{array}$ & 0.09 & $\begin{array}{l}-0.0008 \\
(-0.96)\end{array}$ & -1.23 \\
\hline$\beta$ & $\begin{array}{l}0.820 \\
(15.58)\end{array}$ & 18.77 & $\begin{array}{l}0.659 \\
(18.52)\end{array}$ & 17.84 \\
\hline $\mathrm{M} \gamma_{1}$ & $\begin{array}{l}-0.012 \\
(-2.30)\end{array}$ & -2.10 & $\begin{array}{l}0.017 \\
(2.79)\end{array}$ & 2.58 \\
\hline $\mathrm{M} \gamma_{2}$ & $\begin{array}{l}-0.002 \\
(-0.56)\end{array}$ & -0.89 & $\begin{array}{l}-0.001 \\
(-0.37)\end{array}$ & -0.59 \\
\hline $\mathrm{M} \gamma_{3}$ & $\begin{array}{l}0.001 \\
(0.16)\end{array}$ & 0.39 & $\begin{array}{l}-0.003 \\
(-0.84)\end{array}$ & -0.59 \\
\hline $\mathrm{M} \gamma_{4}$ & $\begin{array}{l}-0.008 \\
(-0.99)\end{array}$ & -1.19 & $\begin{array}{l}-0.004 \\
(-0.49)\end{array}$ & -0.31 \\
\hline $\mathrm{M} \gamma_{23}$ & $\begin{array}{l}-0.001 \\
(-0.10)\end{array}$ & -0.08 & $\begin{array}{l}-0.004 \\
(-0.73)\end{array}$ & -0.88 \\
\hline CEW & $\begin{array}{l}-0.021 \\
(-2.58)\end{array}$ & & $\begin{array}{l}0.008 \\
(0.66)\end{array}$ & \\
\hline PA & $\begin{array}{l}-0.009 \\
(-1.02)\end{array}$ & & $\begin{array}{l}-0.009 \\
(-0.82)\end{array}$ & \\
\hline
\end{tabular}

Columns 2 and 4 give the mean cumulative abnormal returns around the quarterly review for stocks avoiding deletion from, failing to be included in, the FTSE 100 Index. The CAR are obtained from the model $R_{i t}=\alpha_{i}+\beta_{i} R_{m t}+\sum_{j=1}^{4} \gamma_{i j} D_{i j t}+\varepsilon_{i t}$ estimated over the period $t-17$ to $t+150$, where $R_{i t}$ is the equally weighted return to event portfolio $i$, and $R_{m t}$ is the return to the market, on day t. The mean of the four dummy coefficients $\mathrm{M} \gamma 1$... M $\gamma 4$ represent the mean cumulative abnormal return across days $\mathrm{t}-17$ to $\mathrm{t}$ $-7, t-6$ to $t-4, t-3$ to $t-1$ and $t$ to $t+20 . M \gamma_{23}$ is the mean cumulative abnormal return across days $t-6$ to $\mathrm{t}-1$. Associated $\mathrm{t}$-statistics are in parentheses, $\mathrm{t}=\mathrm{M} \gamma_{\mathrm{j}} / \operatorname{SE}\left(\gamma_{\mathrm{j}}\right)$, where $\operatorname{SE}\left(\gamma_{\mathrm{j}}\right)$ is the cross-sectional standard error of the respective regression coefficients. CEW represents the mean cumulative abnormal return across the complete event window $(t-17$ to $t+20)$. PA represents the post-announcement mean cumulative abnormal return ( $t-6$ to $t+20)$. Columns 3 and 5 give $t$-statistics for tests of the significance of the estimated t-statistics, where $t\left(\gamma_{j}\right)=\frac{\text { Mean of } t\left(\gamma_{i j}\right)}{\operatorname{SD~of~} t\left(\gamma_{i j}\right) / \sqrt{N}}$. 
Table V Liquidity effects around the quarterly review for the 'nearly' firms

\begin{tabular}{|c|c|c|c|c|}
\hline & Nearly out & & Nearly il & \\
\hline & & $\mathrm{t}\left(\gamma_{\mathrm{j}}\right)$ & & $t\left(\gamma_{j}\right)$ \\
\hline$\alpha$ & $\begin{array}{l}-0.195 \\
(-6.33)\end{array}$ & -3.88 & $\begin{array}{l}-0.195 \\
(-4.22)\end{array}$ & -4.20 \\
\hline$\beta$ & $\begin{array}{l}1.171 \\
(29.02)\end{array}$ & 18.68 & $\begin{array}{l}1.180 \\
(19.99)\end{array}$ & 16.55 \\
\hline $\mathrm{M} \gamma_{1}$ & $\begin{array}{l}-0.010 \\
(-0.37)\end{array}$ & -0.64 & $\begin{array}{l}.068 \\
(2.34)\end{array}$ & 2.30 \\
\hline $\mathrm{M} \gamma_{2}$ & $\begin{array}{l}.009 \\
(1.35)\end{array}$ & 1.36 & $\begin{array}{l}.007 \\
(0.69)\end{array}$ & 0.66 \\
\hline $\mathrm{M} \gamma_{3}$ & $\begin{array}{l}.030 \\
(3.91)\end{array}$ & 3.79 & $\begin{array}{l}-0.006 \\
(-0.59)\end{array}$ & -0.67 \\
\hline $\mathrm{M} \gamma_{4}$ & $\begin{array}{l}.038 \\
(1.08)\end{array}$ & 1.11 & $\begin{array}{l}-0.005 \\
(-0.11)\end{array}$ & -0.13 \\
\hline $\mathrm{M} \gamma_{23}$ & $\begin{array}{l}0.039 \\
(3.28)\end{array}$ & 3.26 & $\begin{array}{l}0.001 \\
(0.02)\end{array}$ & 0.0 \\
\hline CEW & $\begin{array}{l}.067 \\
(1.10)\end{array}$ & & $\begin{array}{l}.065 \\
(0.89)\end{array}$ & \\
\hline PA & $\begin{array}{l}.078 \\
(2.06)\end{array}$ & & $\begin{array}{l}-0.004 \\
(-0.07)\end{array}$ & \\
\hline
\end{tabular}

Columns 2 and 4 give the mean cumulative abnormal volume around the quarterly review for stocks avoiding deletion from, failing to be included in, the FTSE 100 Index. The CAV are obtained from the model $\mathrm{V}_{\mathrm{it}}=\alpha_{\mathrm{i}}+\beta_{\mathrm{i}} \mathrm{V}_{\mathrm{mt}}+\sum_{\mathrm{j}=1}^{4} \gamma_{\mathrm{ij}} \mathrm{D}_{\mathrm{ijt}}+\varepsilon_{\mathrm{it}}$ estimated over the period $\mathrm{t}-147$ to $\mathrm{t}+20$, where $\mathrm{V}_{\mathrm{it}}$ is the mean trading volume for event portfolio $\mathrm{i}$, and $\mathrm{V}_{\mathrm{mt}}$ is the volume to the market, on day $\mathrm{t}$. Volume is the logarithm of the value of shares traded divided by the logarithm of the value of shares outstanding. The mean of the four dummy coefficients $\mathrm{M} \gamma 1 \ldots \mathrm{M} \gamma 4$ represent the mean cumulative abnormal volume across days $\mathrm{t}-17$ to $\mathrm{t}-7, \mathrm{t}-6$ to $\mathrm{t}-4, \mathrm{t}-3$ to $\mathrm{t}-1$ and $\mathrm{t}$ to $\mathrm{t}+20 \mathrm{M} \gamma_{23}$ is the mean cumulative abnormal volume across days $t-6$ to $t-1$. Associated t-statistics are in parentheses, $t=M \gamma_{j} / \operatorname{SE}\left(\gamma_{j}\right)$, where $\operatorname{SE}\left(\gamma_{j}\right)$ is the cross-sectional standard error of the respective regression coefficients. CEW represent the mean cumulative abnormal volume across the complete event window $(t-17$ to $t+20)$. PA represents the postannouncement mean cumulative abnormal volume $(t-6$ to $t+20)$. Columns 3 and 5 give $t$-statistics for tests of the significance of the estimated t-statistics, where $t\left(\gamma_{j}\right)=\frac{\text { Mean of } t\left(\gamma_{i j}\right)}{\operatorname{SD~of~} t\left(\gamma_{i j}\right) / \sqrt{N}}$. 